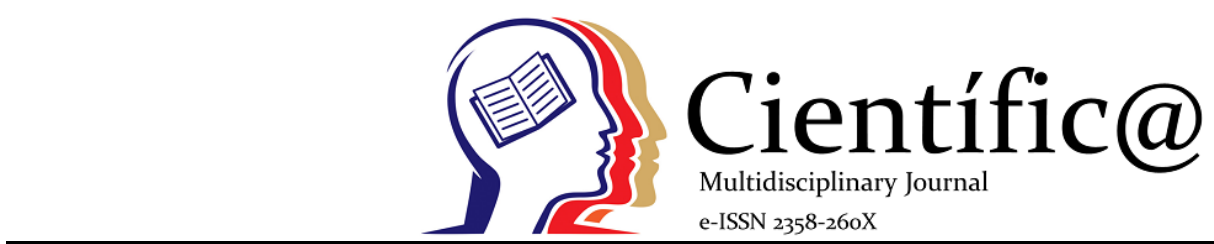

\title{
AVALIAÇÃO FÍSICO-QUÍMICA, MICROBIOLÓGICA E SENSORIAL DE PÃES ENRIQUECIDOS COM FARINHA DE BANANA VERDE COM E SEM CASCA
}

\author{
PHYSICAL CHEMICAL, MICROBIOLOGICAL AND SENSORY EVALUATION OF BREADS \\ ENRICHED WITH GREEN BANANA FLOUR WITH AND WITHOUT PEEL
}

\author{
Marcio Ramatiz Lima Santos ${ }^{1}$; Thales Morgado Almeida ${ }^{1}$
}

${ }^{1}$ Instituto Federal Goiano - Campus Ceres, GO, Brazil.

\section{Info}

Recebido: $10 / 2020$

Publicado: $12 / 2020$

DOI: $10.29247 / 2358-260 X .2020 v 7 i 2.4781$

ISSN: 2358-260X

Palavras-Chave
Musa spp; Panificação. Pão.
Keywords:
Bread; Musa spp.; bakery, functional food.

\begin{abstract}
The objective of this work was to evaluate the physicochemical, microbiological and sensory composition of breads enriched with green banana (Musa ssp.) flour of cultivar "Maçã Tropical", with and without peel. Banana is one of the most consumed fruits worldwide, being produced in the majority of tropical countries to human consumption. The presence of three different natural sugars (saccharose, fructose and glucose) make it a good source of energy to the organism. The unripe fruits were classified, washed, sanitized, rinsed, sliced ( 1 to $2 \mathrm{~mm}$ of thick) and submerged in $0.5 \%$ citric acid solution. In the following steps, were prepared five formulations of bread using green banana flour with peel $(0 \%$;
\end{abstract} $10 \%$ and 15\% GBP) and without peel flour (10\% and 15\% GBF). The breads were ovened, packed and stored until the analysis. The results of pH showed there was a statistical difference between GBP and GBF, with 5.52 and 5.16 , respectively. The titratable acidity of GBP was 0.60 g. 100 g-1, presenting statistical difference from GBF (1.21 g.100 g-1). To ash levels, the treatment GBF 10\% (0.90 g.100 g-1) presented the minor value, differing statiscally from the others formulations. It was observed an increase of titratable acidity of bread with the addition of GBP $15(1.10 \%)$ and GBF $15(0.99 \%)$ compared to control (0.83\%). To humidity, a similar effect was observed with the addition of GBP 15 (22.60\%) and GBF 15 (20.22\%) compared to control (14.81\%). For sensory analysis, the controle presented higher score of acceptance index (86.44\%) followed by treatment GBF 10 (81.16\%) and GBF $10(74.67 \%)$, respectivally. Tjhe others treatments did get socre lower than $70 \%$. All banana flour and all bread formulations do not presented microbiological contaminants. The physical and chemical parameters analyzed attend to Brazilian legislation.

\section{Resumo}

O objetivo deste trabalho foi avaliar a composição físico-química, microbiológica e sensorial de pães enriquecidos com farinha de banana verde (Musa ssp.) da cultivar "Maçã Tropical", com e sem casca. A banana é uma das frutas mais consumidas no mundo, sendo produzida na maioria dos países tropicais para consumo humano. A presença de três diferentes açúcares naturais (sacarose, frutose e glicose) o tornam uma boa fonte de energia para o organismo. Os frutos verdes foram classificados, lavados, sanitizados, enxaguados, fatiados (1 a $2 \mathrm{~mm}$ de espessura) e imersos em solução de ácido cítrico 0,5\%. Nas etapas seguintes, foram preparadas cinco formulações de pães utilizando farinha de banana verde com casca (0\%; 10\% e 15\% FBC) e sem farinha de casca (10\% e $15 \%$ FBS). Os pães foram cozidos no forno, embalados e armazenados até a análise. Os resultados de pH mostraram que houve diferença estatística entre FBC e FBS, com 5,52 e 5,16, respectivamente. A acidez titulável do FBC foi de 0,60 g.100 g-1, apresentando diferença estatística do FBS (1,21 g.100 g-1). Para os níveis de cinzas, o tratamento FBS $10 \%$ (0,90 g.100 g-1) apresentou o menor valor, diferindo estatisticamente das demais formulações. Observou-se aumento da acidez titulável do pão com adição de FBC 15 (1,10\%) e FBS 15 (0,99\%) em relação ao controle $(0,83 \%)$. Para a umidade, efeito semelhante foi observado com a adição de FBC 15 (22,60\%) e FBS 15 (20,22\%) em relação ao controle (14,81\%). Para a análise sensorial, o controle apresentou maior escore de índice de aceitação (86,44\%) seguido do tratamento FBS 10 (81,16\%) e FBS 10 (74,67\%), respectivamente. Os outros tratamentos obtiveram um valor inferior a 70\%. Todas as formulações de farinha de banana e as formulações de pães não apresentaram contaminantes microbiológicos. Os parâmetros físicos e químicos analisados atendem à legislação brasileira. 


\section{INTRODUÇÃO}

A banana é uma das frutas mais consumidas no mundo e é um dos alimentos mais comuns na mesa dos brasileiros, sua produção é uma atividade de grande importância econômica no agronegócio mundial, gerando fonte de renda aos produtores rurais. Com o aumento da informação tecnológica no Brasil, cresce a cada dia o número de bananicultores, que embora sejam em sua maioria agricultores familiares, existe uma crescente diversidade de pequenos, médios e grandes empresários adotando essa atividade (Dantas et al., 2015).

Por ser bastante difundida, a banana é cultivada em todos os estados brasileiros, sendo considerada o segundo fruto mais produzido no Brasil, tendo cerca de 460 mil hectares plantados rendendo cerca de 6.7 milhões de toneladas segundo o Levantamento Sistemático da Produção Agrícola (LSPA), do IBGE. Apesar disto o Brasil ainda é o quarto maior produtor de bananas do mundo perdendo para a Índia (29,124 milhões de toneladas), China (13,066 milhões de toneladas) e Indonésia (7,007 milhões de toneladas) (Kist et al., 2018).

O fruto de banana é uma rica fonte energética, com alto valor nutricional e de fácil digestão, altos teores de carboidratos, açúcares e amido, contendo ainda consideráveis teores de vitamina A, B1, B2 e C e de sais minerais como potássio, fósforo, cálcio, sódio e magnésio, entre outros em menores quantidades (Matsuura et al., 2004).

Durante a vida os seres humanos necessitam de uma alimentação saudável e rica em nutrientes, isto é possível através da utilização de partes dos alimentos que normalmente são jogados fora. A utilização de talos, folhas e cascas de frutas, é de suma importância, pois além de reduzir gastos com alimentos, eles melhoram a qualidade nutricional do que é consumido e reduzem o desperdício (Gondim et al., 2005).
A utilização de partes não convencionais dos alimentos como as cascas de bananas por exemplo, ajudam na redução de resíduos alimentares, reduzem custos de produção e promovem uma alimentação mais saudável, pois as cascas descartadas possuem alta concentração de vitaminas, minerais e fibras, por vezes maiores do que as polpas das frutas (Costa et al., 2015).

Uma segunda opção é a industrialização da banana quando ainda está verde, na forma de farinhas, reduzindo desta forma a produção de resíduos durante a colheita e o transporte que podem chegar na faixa de $40 \%$ a $50 \%$, pois por ser um fruto climatérico é altamente perecível, possui uma alta taxa respiratória e alta produção de etileno após a colheita (Andrade et al., 2018).

O uso da farinha de banana verde no desenvolvimento de produtos alimentícios é muito vantajosa devido à presença de amido glicêmico que é degradado à glicose por diversas enzimas no trato digestivo e o amido resistente que resiste ao processo digestivo no intestino delgado produzindo compostos fenólicos e antioxidantes importantes ao organismo (Andrade et al., 2018).

O pão (do latim "panis") é, atualmente, o produto mais consumido pela humanidade, especialmente pelas populações ocidentais. A história do pão remonta aos primórdios da civilização, quando o homem ainda era nômade (Freire, 2011). De acordo com o estudo da Consultoria Kantar, os pães industrializados (forma branco e integral, com grãos, de hambúrguer, bisnaguinhas entre diversos outros tipos) estão presentes em $80 \%$ dos lares brasileiros e faz parte de quase $25 \%$ de todas as ocasiões de consumo (refeições e lanches) durante o dia. O destaque é para o café da manhã, momento em que o produto se apresenta em $67,3 \%$ das vezes. Na sequência, vem o lanche da tarde, com 26,7\%. Os frios (presunto e queijo), seguidos de requeijão, estão entre os 
acompanhamentos preferidos em ambas as ocasiões (Monitor Mercantil, 2019).

Diante disso, o objetivo deste trabalho foi avaliar a composição físico-química, microbiológica e sensorial de pães enriquecidos com farinha de banana verde (Musa ssp.) da cultivar "Maçã Tropical", com e sem casca.

\section{MATERIAL E MÉTODOS}

Os produtos foram preparados no setor de processamento de vegetais do Departamento de Agroindústria do Instituto Federal Goiano - Campus Ceres. As análises foram realizadas no Laboratório Instrumental do Instituto Federal Goiano - Campus Ceres. O delineamento utilizado foi inteiramente casualizados, com cinco tratamentos, sendo pães de forma com diferentes concentrações $(0 \%, 15 \%$ e $20 \%)$ com 2 tipos de farinhas de banana verde com casca (FBC) e sem casca (FBS) e três repetições.

\section{Matéria-prima}

Os frutos utilizados como matéria-prima para a elaboração desse projeto foram provenientes do Instituto Federal Goiano - Campus Ceres localizados na região do Vale de São Patrício.

As bananas verdes da cultivar maçã tropical foram classificadas quanto à presença de injúrias físicas. Realizou-se a sanitização das bananas com imersão em hipoclorito de sódio $150 \mathrm{mg} \mathrm{L}^{-1}$ por 15 minutos para diminuição da carga microbiana. Posteriormente as bananas foram enxaguadas em água corrente e potável para eliminar os resíduos do agente sanificante. Em seguida, procedeu-se ao processamento do produto.

\section{Processamento}

A desidratação das bananas foi realizada pelos métodos de secagem em estufa a $56^{\circ} \mathrm{C}$ por 48 horas. $\mathrm{O}$ produto seco foi triturado em um BLENDER com granulometria: farinha fina. Foram elaboradas seis formulações diferindo as concentrações de banana verde com casca e sem casca em pó e os ingredientes foram previamente pesados em balança analítica. A Figura 1 representa o fluxograma de todas as etapas até a obtenção dos pães.

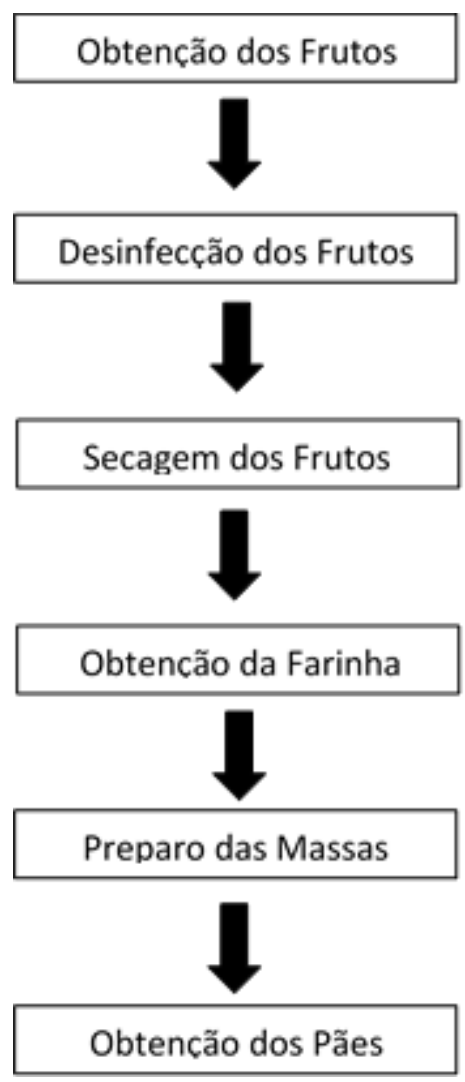

Figura 1: Fluxograma de fabricação dos pães com farinha de banana verde.

O Quadro 1 apresenta as formulações de pães enriquecidos com farinha de banana verde com casca (FCC) e sem casca (FSC), de acordo com a quantidade de farinha de trigo utilizada.

Os ingredientes foram pesados em balança analítica e acondicionados em ambiente limpo e esterilizado. Após a pesagem, foi colocado em uma bacia limpa a farinha de trigo, a farinha de banana, ovo, açúcar, sal e o fermento biológico, foram bem misturados e adicionados por fim o leite e a manteiga. Para melhor homogeneização, utilizou-se uma batedeira doméstica. Após a homogeneização, a massa 
foi trabalhada com rolo de massa, moldada em formato adequado e então foi colocado em formas untadas para pão de forma. Deixou-se a massa descansar, em temperatura ambiente, por 120 minutos até dobrar de tamanho. Os pães foram assados em forno préaquecido a $180^{\circ} \mathrm{C}$ por 30 minutos.

Foram adotadas as boas práticas de fabricação para garantir a obtenção de um alimento seguro.

\section{Análises físico-químicas}

As análises físico-químicas foram realizadas no Laboratório Instrumental do Instituto Federal Goiano - Campus Ceres, em triplicata, para se determinar as composições (Cinza, Umidade, Acidez total titulável ATT, $\mathrm{pH}$ ) de acordo com as normas estabelecidas pelo Instituto Adolfo Lutz (2008).

\section{Análises microbiológicas}

As análises microbiológicas foram realizadas no Laboratório de Microbiologia do Instituto Federal Goiano - Campus Ceres para a determinação de Coliformes Totais e Termotolerantes. As análises microbiológicas foram realizadas pela Técnica de Fermentação em Tubos Múltiplos (TFTM) em triplicata com três diluições $\left(10^{-1} ; 10^{-2}\right.$ e $\left.10^{-3}\right)$, em água peptonada a $0,1 \%$. A quantificação dos microrganismos foi realizada pelo Número Mais Provável (NMP/g). A determinação do Número Mais Provável de coliformes totais e termotolerantes foi realizada através da combinação dos tubos positivos de caldo verde brilhante $2 \%$ (coliformes totais) e caldo E.C (coliformes termotolerantes) o qual estima a quantidade de microrganismos presentes na amostra original com 95\% de probabilidade (Silva et al.,1997).

\section{Análise sensorial}

A análise sensorial foi realizada no Instituto Federal Goiano - Campus Ceres, com 50 provadores, discentes (nível técnico, graduação e pós graduação) e servidores (docentes, técnicos administrativos e terceirizados), dos sexos masculino e feminino, na faixa etária acima de 18 anos. Pessoas que se declararem intolerantes ao glúten, alérgicos a ovos ou com diabetes não participaram da pesquisa.

Como primeira etapa, os participantes voluntários foram submetidos ao Termo de Consentimento Livre e Esclarecido (TCLE) para garantir todos os direitos legais dos participantes. Foi avaliado o perfil dos participantes para obtenção e análise dos dados demográficos de consumo e aceitação do pão com farinha de banana com e sem casca.

O teste de aceitação (teste cego) das amostras dos pães foram realizadas no laboratório experimental da Unidade de Ensino e Produção do Setor de Agroindústria, avaliando os atributos de textura, cor, aroma, aspecto geral e sabor. Os participantes avaliaram os pães utilizando uma escala hedônica estruturada de nove pontos com, 1 (desgostei muitíssimo), 2 (desgostei muito), 3 (desgostei regularmente), 4 (desgostei ligeiramente), 5 (indiferente), 6 (gostei ligeiramente), 7 (gostei regularmente), 8 (gostei muito) e 9 (gostei muitíssimo), para determinar a aceitabilidade e a preferência de acordo com a metodologia proposta por Della Modesta (1994).

Cada amostra para realização das avaliações possuía de 20 a 30 gramas dispostas em copos plásticos descartáveis, codificados com diferentes numerações, sendo colocado à disposição água mineral para enxaguar a boca. Todas as amostras vieram de pães fabricados na manhã do teste e sendo imediatamente armazenados em sacos estéreis, e por fim adicionados em vasilhas esterilizadas para condução do experimento.

As médias obtidas na análise sensorial foram utilizadas para o cálculo do índice de aceitação (IA \%), de acordo com o proposto por Palermo (2015). 
IA $(\%)=($ Média do Atributo/9) $* 100$

\section{Análise estatística}

As análises estatísticas foram realizadas utilizando-se o programa software SISVAR 5.6 e aplicando-se o Teste de Tukey a 5\% de significância para comparar os resultados da análise sensorial e físicoquímica das formulações experimentais, verificando desta forma a interação entre as médias e para a análise microbiológica os dados foram analisados de forma descritiva.

\section{RESULTADOS E DISCUSSÃO}

De acordo com as análises microbiológicas (Tabela 1), pode-se observar os resultados negativos $(<3,0 \mathrm{NMP} / \mathrm{g})$ para os 2 tipos de farinhas de banana com casca (FBC) e sem casca (FBS). Como os pães foram realizados com diferentes concentrações de FBC e FBS, apresentaram contaminação microbiológica $<3,0 \mathrm{NMP} / \mathrm{g}$, tornando-os aptos para o consumo humano. Estes resultados corroboram com Andrade et al. (2018), que obtiveram contaminação <3,0 NMP/g de Coliformes Fecais e Escherichia coli, bolores e leveduras para pães enriquecidos com farinha de banana verde.

Segundo Silva (1997), a presença de Coliformes totais e Escherichia coli em alimentos processados, é considerada uma indicação útil de contaminação póssanitização ou pós-processo, indicando assim, que a adoção das boas práticas de fabricação dos pães durante o processamento foi eficiente.

Tabela 1: Resultados das análises microbiológicas das farinhas FBC e FBS

\begin{tabular}{ll}
\hline Amostras/ Diluição & NMP/g \\
\hline FBC & $<3,0$ \\
FBS & $<3,0$
\end{tabular}

$\mathrm{FBC}=$ Farinha de banana com casca; FBS $=$ Farinha de banana sem casca. Os resultados foram descritos de forma descritiva.

Tabela 2: Resultados das análises microbiológicas dos pães com FBC e FBS

\begin{tabular}{ll}
\hline Amostras/ Diluição & NMP/g \\
\hline $0 \%$ & $<3,0$ \\
FBC $10 \%$ & $<3,0$ \\
FBS 10\% & $<3,0$ \\
FBC $15 \%$ & $<3,0$ \\
FBS $15 \%$ & $<3,0$ \\
\hline
\end{tabular}

$\mathrm{FBC}=$ Farinha de banana com casca; FBS $=$ Farinha de banana sem casca. Os resultados foram descritos de forma descritiva.

De acordo com a RDC No 12/2001, o limite estabelecido para farinhas, féculas e fubá é de $10^{2}$ $\mathrm{NMP} / \mathrm{g}$. Os resultados encontrados neste projeto para avaliação microbiológica foram inferiores ao supracitados, desta forma, confirma-se que os procedimentos adotados para higiene e sanitização na elaboração dos pães e farinhas foram eficientes, estando, portanto, dentro dos padrões estabelecidos pela legislação vigente (Brasil, 2001).
Santos et al. (2010), realizaram a análise microbiológica da farinha de banana verde durante o período de 90 dias, armazenadas à temperatura ambiente, em que os valores para bolores e leveduras foi $<10 \mathrm{UFC} / \mathrm{g}$ e coliformes totais e termotolerantes foi $<3,0 \mathrm{NMP} / \mathrm{g}$, estando desta forma aptas para o consumo humano.

A Tabela 3 apresenta os resultados da análise físico-química para as farinhas de banana verde com e 
sem casca. Verificou-se que para acidez total titulável apresentou diferença estatística significativa em que a FBC foi de 1,21 \% m/v enquanto a FBS apresentou $0,60 \% \mathrm{~m} / \mathrm{v}$. Esses resultados ratificam com Borges et al. (2009), trabalhando com a caracterização da farinha de banana verde, em que obtiveram um valor equiparável $(0,63 \% \mathrm{~m} / \mathrm{v})$ para farinha de banana verde sem casca.

Segundo Zhang et al. (2005), cerca de $75 \%$ da farinha de banana verde é composta por amido resistente, desta forma o aumento do teor de acidez da FBC $(1,21 \% \mathrm{~m} / \mathrm{v})$ pode ter sido ocasionado devido à presença da casca que elevou os resultados. Alcantara et al. (2014), em estudos com farinha da casca de banana da cultivar Maça e Prata, obtiveram respectivamente valores médios de $5,13 \% \mathrm{~m} / \mathrm{v}$ e $5,42 \% \mathrm{~m} / \mathrm{v}$ para acidez total titulável.

A Tabela 3 mostra os resultados para a análise de $\mathrm{pH}$, em que foi constatado diferença estatística significativa, com os valores médios de 5,70 para FBC e 6,05 para FBS. Estes resultados ratificam com alguns estudos realizados, tais como Borba et al. (2005), em que constatou $\mathrm{pH}$ médio de 4,38 na farinha de batata doce e 5,80 para farinha de arroz. Na pesquisa feita por Savlak et al. (2016), obtiveram pH médio de 5,65 ao trabalharem com farinha de banana verde (Cavendish).

Estes resultados obtidos diferiram de Borges et al. (2009), que em uma pesquisa sobre a caracterização da farinha de banana verde (Prata) obteve um valor médio de pH de 5,30 e Fernandes (2006), ao estudar a composição da farinha da casca da batata, verificou um pH médio de 4,96.

Na Tabela 3 observa-se os valores médios dos teores de umidade, apresentando diferença estatística significativa para FBC (9,54 g.100 g-1) e FBS (9,81 g.100 $\left.\mathrm{g}^{-1}\right)$. Segundo a instrução normativa $N^{\circ} 8$, de 2 de junho de 2005, o limite máximo permitido de umidade para a farinha de trigo, pela legislação brasileira, é de 15\% (Brasil, 2005). Desta forma as farinhas de banana verde com e sem casca encontravam-se dentro dos padrões aceitáveis de acordo com a ANVISA.

Os valores para o teor de umidade encontrados mostraram-se inferiores aos estudos realizados por Pires et al. (2014), que obtiveram 11,4\% com farinha de banana verde.

Quanto ao teor de cinzas, de acordo com a Tabela 3, as formulações FBC e FBS apresentaram diferença estatística significativa com valores respectivos de 3,84 g.100 $\mathrm{g}^{-1}$ e 2,63 g.100 g-1. Dados semelhantes aos encontrados por Fasolin et al. (2007), com 2,62 g.100 $\mathrm{g}^{-1}$ para farinha de banana verde e Borges et al. (2009), com 2,59 g.100 g-1 em seu estudo sobre caracterização de farinha de banana verde, em que concluíram que a casca confere maior quantidade de resíduos inorgânicos remanescentes (minerais).

Tabela 3: Resultados da análise físico-química das farinhas FBC e FBS (acidez total titulável, umidade e cinzas).

\begin{tabular}{lllll}
\hline Amostra & ATT (\%m/v) & pH & Umidade (\%) & Cinzas (\%) \\
\hline FBC & $1,21 \pm 0,13 \mathrm{a}$ & $5,70 \pm 0,02 \mathrm{~b}$ & $9,54 \pm 0,14 \mathrm{~b}$ & $3,84 \pm 0,15 \mathrm{a}$ \\
FBS & $0,60 \pm 0,13 \mathrm{~b}$ & $6,05 \pm 0,02 \mathrm{a}$ & $9,81 \pm 0,14 \mathrm{a}$ & $2,63 \pm 0,15 \mathrm{~b}$ \\
Média Geral & 0,91 & 5,87 & 9,67 & 3,23 \\
CV & 14,46 & 0,33 & 1,45 & 4,55
\end{tabular}

Letras diferentes na mesma coluna indicam que houve diferença estatística significativa entre os tratamentos, para o Teste de Tukey $(\mathrm{p}<0,05)$. 
Analisando os dados da Tabela 4, para acidez total titulável (ATT) houve diferença estatística significativa $(\mathrm{p}<0,05)$, em que o pão com FBC 15\% foi maior $(1,10 \% \mathrm{~m} / \mathrm{v})$ que os demais, possivelmente ocasionado pela composição da polpa e da casca.

Observando os dados apresentados na Tabela 4, todas as formulações de pães com FBC e FBS estavam abaixo de 22,6\% de umidade, comparando com a legislação atual, todos os tratamentos estavam dentro do padrão exigido pela ANVISA - Resolução $n^{\circ}$ 90 (2000), que determina o limite máximo de 38\% de umidade para pães produzidos exclusivamente com farinha de trigo comum ou farinha de trigo especial.

Em relação ao pH, observou-se uma redução nos valores associados ao aumento das porcentagens de farinha de banana verde nos pães FBC e FBS, o pão que não houve adição de farinha de banana verde apresentou $\mathrm{pH}$ de 5,87. No estudo feito por Borges et al. (2010) com pré mistura de bolos elaboradas com farinha da casca de banana verde, houve uma redução do pH com a adição de $60 \%$ de farinha em comparação à testemunha.

Para os valores encontrados de umidade de acordo com os dados apresentados na Tabela 4, os pães com FSC 10\% não diferiram estatisticamente da
Testemunha nem do FSC 15\%. As formulações FCC 10\%, FCC 15\% e FSC15 \% não diferiram entre si. Segundo Andrade et al. (2017), o aumento da umidade nos pães com farinha de banana verde pode estar associado ao aumento de absorção de água em sua composição.

De acordo com Silva et al. (2014), na fabricação de pães enriquecidos com farinha de banana verde (Nanica) observaram aumento do teor de umidade com adição de farinha de banana verde, que possivelmente foi ocasionada pelo amido presente em sua composição.

Como observado na Tabela 4 os teores de cinzas apresentaram diferença estatística significativa para as formulações FCC 10\% e FCC 15\% obtiveram respectivamente os valores de 1,11 g.100 $\mathrm{g}^{-1}$ e 1,17 g.100 $\mathrm{g}^{-1}$, enquanto os pães com FSC 10\% e 15\% apresentaram 0,9 g.100 $\mathrm{g}^{-1}$ e $1,04 \quad$ g.100 $\mathrm{g}^{-1}$ respectivamente, provavelmente ocasionado quantidade de resíduos inorgânicos remanescentes da queima da matéria orgânica. O mesmo foi observado por Fasolin et al. (2007), em estudos com biscoitos produzidos com farinha de banana verde com o aumento significativo dos teores de cinzas com a adição de farinha de banana verde (Pacovan).

Tabela 4: Resultados da análise físico-química dos pães com FCC 10 \% e 15 \% e FSC $10 \%$ e 15 \% (acidez total titulável, $\mathrm{pH}$, umidade e cinzas).

\begin{tabular}{lllll}
\hline Análise & ATT(\%m/v) & pH & Umidade (\%) & Cinzas (\%) \\
\hline Testemunha & $0,83 \pm 0,08 \mathrm{e}$ & $5,87 \pm 0,1 \mathrm{a}$ & $14,81 \pm 1,52 \mathrm{c}$ & $0,90 \pm 0,06 \mathrm{~b}$ \\
FCC10\% & $1,04 \pm 0,08 \mathrm{~b}$ & $5,13 \pm 0,1 \mathrm{~cd}$ & $22,47 \pm 1,52 \mathrm{a}$ & $1,11 \pm 0,06 \mathrm{a}$ \\
FCC15\% & $1,10 \pm 0,08 \mathrm{a}$ & $4,90 \pm 0,1 \mathrm{~d}$ & $22,60 \pm 1,52 \mathrm{a}$ & $1,17 \pm 0,06 \mathrm{a}$ \\
FSC10\% & $0,95 \pm 0,08 \mathrm{~d}$ & $5,57 \pm 0,1 \mathrm{c}$ & $17,29 \pm 1,52 \mathrm{bc}$ & $0,90 \pm 0,06 \mathrm{~b}$ \\
FSC15 \% & $0,99 \pm 0,08 \mathrm{c}$ & $5,30 \pm 0,1 \mathrm{~b}$ & $20,22 \pm 1,52 \mathrm{ab}$ & $1,04 \pm 0,06 \mathrm{ab}$ \\
Média Geral & 0,98 & 5,35 & 19,48 & 1,02 \\
CV \% & 1,08 & 1,79 & 7,81 & 6,09 \\
\hline
\end{tabular}

Letras diferentes na mesma coluna indicam que houve diferença estatística significativa entre os tratamentos segundo ASSISTAT no nível de $5 \%$ de significância. FCC= Pão com farinha de banana verde com casca; FSC= Pão com farinha de banana verde sem casca. 
Os resultados referentes a avaliação sensorial dos pães formulados com diferentes percentuais de FBC e FBS estão representados na Tabela 5.

Para Textura, a Testemunha apresentou maior valor $(8,06)$ e FSC $10 \%$ (7,70) não apresentaram diferença estatística significativa entre si, mas apresentaram diferença significativa das formulações FSC $15 \%(6,22)$, FCC 10\% $(6,52)$ e FCC 15\% (5,9), provavelmente ocasionada pela maior adição da farinha de banana verde e pela presença da casca em sua composição. Dados que diferiram dos resultados observados por Borges (2007), em que a adição de farinha de banana verde favoreceu a textura, e apresentou maiores notas na fabricação de bolos com $0 \%, 15 \%, 30 \%, 45 \%$ e $60 \%$ de farinha de banana verde obtiveram valores de (6,63), (6,44), $(6,28),(7,11)$ e $(7,57)$ respectivamente.

Para os valores encontrados no atributo Cor, verificou-se que as formulações testemunha e FSC 10\% não diferiram entre si, mas apresentaram as maiores notas, 7,98 e 7,64 respectivamente. A formulação FCC $10 \%$ apresentou maior nota $(6,88)$ quando comparado às formulações FSC 15\% (5,90) e FCC 15\% $(5,20)$, provavelmente foi ocasionado devido à quantidade de farinha de banana verde, que pode ter influenciado em cores mais escuras dos pães e nas piores notas. De acordo com Andrade et al. (2018), no requisito cor, quanto maior a adição de farinha de banana verde menores foram as notas dadas pelos avaliadores, devido à coloração mais escura apresentada.

No atributo Aroma, as formulações não apresentaram diferenças estatísticas significativas entre si, demonstrando desta forma não terem sido influenciadas pela presença ou ausência de FBC ou FBS em nenhuma das concentrações. Dados que corroboram com Borges (2007), que observou que não houve influência no aroma de bolos com até 60\% farinha de banana verde.

$\mathrm{Na}$ variável Sabor, a formulação testemunha diferiu das demais, com a maior nota de aceitabilidade $(8,14)$, já as formulações FSC 10\% $(7,08)$ e FCC 10\% $(6,40)$ não diferiram significativamente entre si, mas apresentaram maiores notas quando comparadas às FSC 15\% (5,44) e FCC 15\% (4,90). Estes dados diferem de Borges (2007), em que observou que o aroma e sabor não são influenciados pela adição de farinha de banana verde. Fernandes et al. (2015), em estudos sobre adição de farinha de banana verde $(0 \%, 4 \%, 8 \%, 12 \%, 16 \%$ e $20 \%$ em pães de queijo constataram diferenças estatísticas significativas para aroma com valores de $(7,23), \quad(6,84), \quad(6,57), \quad(5,63), \quad(5,95) \quad$ e respectivamente e para sabor, em que as formulações $0 \%(6,90), 4 \%(6,61)$, e $8 \%(6,28)$ não diferiram entre si mas diferiram das formulações com 12\% $(5,38)$ 16\% $(5,23)$ e $20 \%(4,63)$.

Em Aspecto Geral, as formulações FSC 10\% $(7,00)$, FSC 15\% $(6,80)$ e FCC 10\% $(6,78)$ não diferiram estatisticamente entre si, mas diferiram em relação ao FCC $15 \%$ que recebeu a menor nota $(6,62)$ que corresponde a "gostei ligeiramente", estes dados contrastam com os encontrados por Freitas et al. (2017), em que não obtiveram diferenças em pães de mel com farinha de banana verde.

Em relação ao Índice de Aceitação, observouse que a testemunha apresentou o maior IA $(86,44 \%)$, seguido do FSC 10\% (81,16\%) e FCC 10\% (74,66\%), sendo estes considerados aceitos pelos provadores. As formulações FSC 15\% (69,77 \%) e FCC 15\% (65,68\%) não foram consideradas aceitas pelos provadores por apresentarem médias menores que $70 \%$. 
Tabela 5: Resultados da análise sensorial dos pães enriquecidos com farinha de banana verde com e sem casca.

\begin{tabular}{lllllll}
\hline Análise & Textura & Cor & Aroma & Sabor & $\begin{array}{l}\text { Aspecto } \\
\text { Geral }\end{array}$ & $\begin{array}{l}\text { Índice de } \\
\text { Aceitação } \\
(\%)\end{array}$ \\
\hline Testemunha & $8,06 \pm 1,54 \mathrm{a}$ & $7,98 \pm 1,37 \mathrm{a}$ & $7,14 \pm 1,58 \mathrm{a}$ & $8,14 \pm 1,54 \mathrm{a}$ & $7,58 \pm 1,54 \mathrm{a}$ & 86,44 \\
FSC 10\% & $7,70 \pm 1,54 \mathrm{a}$ & $7,64 \pm 1,37 \mathrm{a}$ & $7,10 \pm 1,58 \mathrm{a}$ & $7,08 \pm 1,54 \mathrm{~b}$ & $7,00 \pm 1,54 \mathrm{ab}$ & 81,16 \\
FSC 15\% & $6,22 \pm 1,54 \mathrm{~b}$ & $5,9 \pm 1,37 \mathrm{c}$ & $7,04 \pm 1,58 \mathrm{a}$ & $5,44 \pm 1,54 \mathrm{c}$ & $6,80 \pm 1,54 \mathrm{ab}$ & 69,77 \\
FCC 10\% & $6,52 \pm 1,54 \mathrm{~b}$ & $6,88 \pm 1,37 \mathrm{~b}$ & $7,02 \pm 1,58 \mathrm{a}$ & $6,40 \pm 1,54 \mathrm{~b}$ & $6,78 \pm 1,54 \mathrm{ab}$ & 74,66 \\
FCC 15\% & $5,90 \pm 1,54 \mathrm{~b}$ & $5,20 \pm 1,37 \mathrm{c}$ & $6,94 \pm 1,58 \mathrm{a}$ & $4,90 \pm 1,54 \mathrm{c}$ & $6,62 \pm 1,54 \mathrm{~b}$ & 65,68 \\
Média Geral & 6,88 & 6,72 & 7,05 & 6,39 & 6,96 & 75,54 \\
CV \% & 22,42 & 20,35 & 22,36 & 24,16 & 22,09 & - \\
\hline
\end{tabular}

Letras diferentes na mesma coluna indicam que houve diferença estatística significativa entre os tratamentos segundo ASSISTAT no nível de $5 \%$ de significância. PSC= pão com farinha de banana sem casca; PCC= pão com farinha de banana com casca.

\section{CONCLUSÕES}

Após a análise dos dados obtidos conclui-se:

As análises microbiológicas tanto das farinhas de banana verde quanto das formulações de pães apresentaram-se dentro dos parâmetros determinados pela legislação brasileira.

Os resultados das análises físico-químicas das farinhas de banana verde com e sem casca estavam de acordo com a Instrução Normativa $n^{\circ} 8 / 2005$ do MAPA.

As formulações dos pães com adição de farinha de banana verde com e sem casca alteraram as propriedades físico-químicas principalmente em relação à acidez.

Os resultados da análise sensorial indicaram que os tratamentos FSC 10\% e FCC 10\% apresentaram os maiores índices de aceitação, sendo portanto, as formulações indicadas para fabricação.

\section{AGRADECIMENTOS}

Agradecemos ao Instituto Federal Goiano Campus Ceres pela bolsa PIBIC.

\section{REFERÊNCIAS}

Alcantara BM, Castilho LG, Clemente E. Desenvolvimento e análise físico-química da farinha da casca, da casca in natura e da polpa de banana verde das cultivares maçã e prata. exata. 2014; 7: 107-114. Doi: 10.18674/exacta.v7i2.1353.

Andrade BA, Perius DB, De Mattos NV, De Mello LM, Melano MS. Produção de farinha de banana verde (Musa spp.) para aplicação em pão de trigo integral. Brazilian Journal of Food Technology. 2018; 21:1-10. Doi: 10.1590/1981-6723.5516.

ANVISA (Agência Nacional de Vigilância Sanitária) Resolução $\mathrm{n}^{\circ}$ 90, de 18 de outubro de 2000. Regulamento técnico para fixação de identidade e qualidade de pão.

Borba AM, Sarmento SBS, Leonel M. Efeito dos parâmetros de extrusão sobre as propriedades funcionais de extrusados de farinha de batatadoce. Ciênc. Tecnol. Aliment. 2005; 25: 835-843. Doi: 10.1590/S0101-20612005000400034.

Borges AM, Pereira J, Lucena EMP. Caracterização da farinha de banana verde. Ciênc. Tecnol. Aliment. 2009; 29: 333-339. Doi: 10.1590/S010120612009000200015.

Borges AM, Pereira J, Silva Júnior A, Lucena EMP, Sales JC. Estabilidade da pré-mistura de bolo elaborada com $60 \%$ de farinha de banana verde. Ciência e Agrotecnologia. 2010; 34:173-181. Doi: 10.1590/s1413-70542010000100022.

Borges AM. Caracterização e estabilidade de prémisturas para bolos à base de farinha de banana verde [tese]. Lavras: Universidade Federal de Lavras; 2007.

BRASIL. Ministério da Agricultura, Pecuária e Abastecimento. Instrução Normativa no 8, de 2 
de junho de 2005. Regulamento técnico de identidade e qualidade da farinha de trigo. Diário Oficial da República Federativa do Brasil, Brasília, DF, n. 105, p. 91, 2005.

BRASIL. Ministério da Saúde. Resolução - RDC N 12 , de 02 de janeiro de 2001. Aprova o "Regulamento técnico: princípios gerais para o estabelecimento de critérios e padrões microbiológicos para alimentos e seus anexos". Órgão emissor: ANVISA: Agência Nacional de Vigilância Sanitária. Disponível em: $<$ www.anvisa.gov.br>. Acesso em: 01 de março de 2020 .

Costa RTRV, Nascimento AM, Araújo AS, Silva-Neto JC, Dantas CO. Petit Gateau com recheio de doce de banana com e sem casca. Revista Verde de Agroecologia e Desenvolvimento Sustentável. 2015; 10: 15-20. Doi: $10.18378 /$ rvads.v10i2.3402.

Dantas JLL, Silva SO, Soares Filho WS, Carvalho PCL. Filogenia, história, evolução, distribuição geográfica e habitat. 1 ed. O Agronegócio da banana: Embrapa; 2015.

Della-Modesta RC. Manual de análise sensorial de alimentos e bebidas. Rio de Janeiro: EMBRAPACTAA;1994.

Fasolin LH, De Almeida GC, Castanho PS, NettoOliveira ER. Biscoitos produzidos com farinha de banana: Avaliações química, física e sensorial. Ciênc. Tecnol. Aliment. 2007; 27:524-529. Doi: 10.1590/S0101-20612007000300016.

Fernandes AF. Utilização da farinha de casca de batata inglesa (Solanum tuberosum L.) na elaboração de pão integral [dissertação]. Lavras: Universidade Federal de Lavras; 2006.

Fernandes DDS, Del Bem MS, Sorroche C, Leonel M, Leonel S. Elaboração de pão de queijo adicionado com farinha de banana verde: características físicas e sensoriais. Revista Raízes e Amidos Tropicais. 2015; 11: 56-65. Doi: 10.17766/1808-981X.2015v11n1p56-65.

Freire, FCO. A Deterioração Fúngica de Produtos de Panificação no Brasil. Comunicado Técnico 174. Embrapa, Outubro/2011. ISSN 1679-6535. Disponível em: https://www.infoteca.cnptia.embrapa.br/bitstre am/doc/907492/1/COT11010.pdf. Acessado em: $23 / 10 / 2020$.
Freitas MCJ, Silveira GE, Veras LS, Santos GFF. Pães de mel elaborados com farinha de diferentes variedades de banana verde. Demetra: Food, Nutrition \& Health. 2017; 12: 465-482. Doi: 10.12957/demetra.2017.25127.

Gondim JAM, Moura MDFV, Dantas AS, Medeiros RLS, Santos KM. Composição centesimal e de minerais em cascas de frutas. Food Science and Technology. 2005; 25: 825-827. Doi: 10.1590/S0101-20612005000400032.

IBGE. Instituto Brasileiro de Geografia e Estatística: Produção Agrícola Municipal. 2018.

Kist BB, Santos CE, Carvalho C, Beling RR. Anuário Brasileiro de Horti e Fruti 2019. 1. Santa Cruz do Sul: Editora Gazeta Santa Cruz; 2018.

Matsuura FCAU, Costa JIP, Folegatti MIS. Marketing de banana: preferências do consumidor quanto aos atributos de qualidade dos frutos. Rev. Bras. Frutic. 2004; 26: 48-52. Doi: 10.1590/S010029452004000100014

Monitor Mercantil. Pão industrializado está em 80\% dos lares brasileiros. Revista Eletrônica Monitor Mercantil, Outubro/2019. Disponível: https://monitormercantil.com.br/paoindustrializado-esta-em-80-dos-lares-brasileiros. Acessado em: 23/10/2020.

Pires VCF, Silva FLH, Souza RMS. Parâmetros da secagem da banana pacovan e caracterização físico-química da farinha de banana verde. Revista Verde de Agroecologia e Desenvolvimento Sustentável. 2014; 9: 197-209.

Santos JC, Silva GF, Santos JA, Júnior AMO. Processamento e avaliação da estabilidade da farinha de banana verde. Exacta. 2010; 8: 219224.

Savlak N, Turkey B, Yesilkanat N. Effects of particle size distribution on some physical, chemical and functional properties of unripe banana flour. Food Chemistry. 2016; 213: 180-186. Doi: 10.1016/j.foodchem.2016.06.064.

Silva JP, Netto-Oliveira ER, Pereira SCM, Monteiro ARG. Avaliação físico-química e sensorial de pães produzidos com substituição parcial de farinha de trigo por farinha de banana verde. Revista Brasileira de Pesquisa em Alimentos. 2014; 5:1-7. 
Silva N, Junqueira VCA, Silveira NFA. Manual de métodos de análise microbiológica de alimentos. São Paulo: Livraria Varela; 1997.

Zenebon O, Pascuet NS, Tiglea P. Métodos físicoquímicos para análise de alimentos. 4 ed. São Paulo: Instituto Adolfo Lutz; 2008.
Zhang P, Assobiador RL, BeMiller JN, Hamaker BR. Resistant banana starch: production, physicochemical properties, and digestibility -A review. Carbohydrate Polymers. 2005; 59: 443458. Doi: 10.1016/j.carbpol.2004.10.014. 